Bolm Botânica, Univ. S. Paulo 9: 219-226, 1987

\title{
FLORA DA SERRA DO CIPÓ, MINAS GERAIS:
}

\author{
SIMAROUBACEAE (1)
}

\author{
JOSE RUBENS PIRANI
}

\begin{abstract}
Instituto de Biociências, Universidade de São Paulo, CP 11461 05499 - São Paulo, SP.
\end{abstract}

ABSTRACT - (Flora of the Serra do Cipó, Minas Gerais: Simaroubaceae). The study of the family Simaroubaceae is a part of the project of "Flora of Serra do Cipó, Minas Gerais, Brasil". In that area, the family is represented by the following species: Picramnia glazioviana Engl., P. sellowii Planch. and Simarouba amara Aub1. Keys to the genera and species, descriptions and illustrations, as well as comments on the geographic distribution, phenology and variability of the species are presented.

RESUMO - (Flora da Serra do Cipó, Minas Gerais: Simaroubaceae). o estudo da família Simaroubaceae é parte do levantamento da Flora da Serra do Cipó, Minas Gerais, Brasil. Esta familia está representada naquela área pelas espécies: Picramnia glazioviana Engl., P. sellowii Planch. e Simarouba amara Aubl. São apresentadas chaves para gêneros e espécies, descrições e ilustrações das mesmas, além de comentários sobre sua distribuição geográfica, fenologia e variabilidade.

Key words - Simaroubaceae, Serra do Cipó floristics.

\section{S I MAROUBACEAE}

Árvores ou arbustos, freqüentemente com substâncias amargas na casca. Folhas geralmente alternas, pinadas ou menos freqüentemente simples, desprovidas de glândulas. Inflorescências terminais e/ou axilares, geralmente multifloras, paniculadas ou racemosas, raramente flores solitárias. Flores 3-5(-8)-meras, monóclinas ou díclinas (estas em plantas monóicas ou dióicas), actinomorfas; pétalas 1 ivres, raramente ausentes; androceu isostêmone ou diplostêmone, raramente polistêmone; filetes. livres, às vezes apendiculados na base; estames ausentes ou reduzidos a estaminódios nas flores funcionalmente pistiladas; disco intra-estaminal geralmente presente; gineceu 2-5(-8)-carpelar, apocárpico ou sincárpico, rudimentar ou ausente nas flores funcionalmente estaminadas; óvulos 1-2 por lóculo, raramente mais, geralmente anátropos, colaterais ou superpostos, placentação geralmente axilar; estiletes 1 ivres ou parcial a totalmente coerentes ou unidos. Fruto geralmente com 2-5(-8) carpídios drupáceos, bacáceos ou samoroídeos; semente 1 por lóculo; endosperma ausente ou escasso.

Bibliografia básica - Cronquist (1944), Engler (1874, 1931).

(1) Trabalho feito dentro do planejamento apresentado por Giulietti et al. (1987). 
Chave para os gêneros

1. Estames ou estaminódios 10 , apendiculados na base; flores 5-meras ca. $10 \mathrm{~mm}$ compr.; ovário apocárpico; raque foliar canaliculada; folíolos com ápice geralmente arredondado e nervuras secundárias inconspicuas............... Simarouba

$1^{\prime}$. Estames ou estaminódios 3-5, sem apêndices; fiores 3-5-meras ca. $3 \mathrm{~mm}$ compr.; ovário sincárpico; raque foliar não canaliculada; folíolos com ápice acuminado e nervuras secundárias bem evidentes...................... 2. Picramnia

\section{Simarouba Aub1.(*)}

Simarouba amara Aub1. Hist. P1. Guiane Franç. 2: 860, tab. 331,332 . 1775:

Figs . $1-14$

Nomes vulgares: praíba, paraíba.

Arvoretas a árvores $3,0-8,0 \mathrm{~m}$ a $1 \mathrm{t} \ldots$ Folhas alternas, pari- ou imparipinadas, glabras, $12,0-24,0 \mathrm{~cm}$ compr., raque canaliculada superiormente, avermelhada a castanha; folínlos 9-16, alternos a opostos, subcoriáceos, peciolulados, 3, 0-10,5 cm compr., $1,0-2,8 \mathrm{~cm} 1 \mathrm{arg}$, obovado-oblongos a oblongo-elípticos, ligeiramente assimétricos, ápice arredondado a retuso, margem pouco revoluta, base cuneada, brilhantes na face superior, opacos na inferior, nervuras laterais inconspicuas. Paniculas axilares ou terminais, glabras, eretas, as estaminadas $13,0-20,0 \mathrm{~cm}$ compr., as pistiladas 4,0-10,0 cm compr. Flores 5-meras, 9,0-12,0 $\mathrm{mm}$ compr., amarelo-esverdeadas a avermelhadas, perfumadas, pediceladas; pétalas oval-oblongas, apiculadas, glabras, reflexas. Flores estaminadas: estames 10 , ca. 4,0 mm compr., os alternissépalos menores que os demais; base dos filetes com apêndices ovais densamente pilosos inclinados sobre o disco; disco glabro, espessado; pistilódio rudimentar sobre o disco. Flores pistiladas: estaminódios 10, espatulados, densamente pilosos, com anteras estéreis reduzidas; disco estipitado, glabro; carpelos 5, glabros, yerdes, frouramente conatos axialmente, formando um ovário profundamente 5-1otado; estiletes 5, frouxamente coalescidos, decíduos; estigmas 5, amarelos, divergentes, recurvados no ápice; óvulo 1 por carpelo, subapical. Fruto com 1-5 carpídios drupáceos elipsóides a obovóides, levemente comprimidos lateralmente, carenados, verdes a vináceos, 1,0-2,0 cm compr.; semente 1 por carpídio, cotilédones carnosos.

Material examinado: Santana do Riacho, Serra do Cipó, Rodovia Belo Horizonte - Conceição do Mato Dentro: km 120, Córṛego Duas Pontinhas, CFSC 6118,6119 e 6121, Col.J.R. Pirani

\begin{tabular}{|c|c|c|}
\hline$\overline{(\star)}$ & $\mathrm{Eml}$ & $\mathbf{N}$ \\
\hline & ou 1 & g \\
\hline & L. & $\mathbf{r}$ \\
\hline & $\begin{array}{l}\text { ro: } \\
\text { Po }\end{array}$ & $s$ \\
\hline
\end{tabular}

(1962) trate Simarouba Aub1., Simaba Aubl. e tribo Simaroubeae como seções de Quassia ria dos botânicos consideram-nos como gênee.g. Engler 1874, 1931; Cronquist 1944; alcante 1983 ). 
\& I. Cordeiro, 24.V.1980, fl. fr. (SP, SPF); id., CFSC 6232, Col. A. Furlan \& J.R. Pirani, 8.VI.1980, fl. fr. (SP, SPF); km 128 , CFSC 6171, Col. J.R. Pirani, 6.VI.1980, fl. (SP, SPF); km 129, Ribeirão Capivara, CFSC 6215 e 6220, Col. J.R. Pirani \& A. Furlan, 8.VI.1980, f1. fr. (SP, SPF); km 124, Faz. Palácio, CFSC 6514, Col.J.R. Pirani \& I. Cordeiro, 4.IX.1980, fr. (SP, SPF); $\mathrm{km} \mathrm{121,} \mathrm{Córrego} \mathrm{Indequicé,} \mathrm{CFSC} \mathrm{7228,} \mathrm{Col.} \mathrm{J.R.} \mathrm{Pirani} \mathrm{et} \mathrm{al.,}$ 19.VI.1981, f1. (SP, SPF); km 134, A.P. Duarte 11555, 13.V.1969, f1. (Внмн); id., Mello Barreto 1258 \& Brade, 15.VI.1935, fl. (BHMH, F, R); km 135, A.P. Duarte 2628, 21.IV.1950, fl. (RB, ВНMH).

Espécie de ampla distribuição geográfica, sendo citada para o Panamá (Porter 1973), Venezuela, Suriname, Guiana, Guiana Francesa, Peru, Bolívia e Brasil até Minas Gerais (Cronquist 1944). As árvores desta espécie podem alcançar grande porte, mas na Serra do Cipó atingem no máximo $8 \mathrm{~m}$ de altura. Aqui, aparecem com freqüência regular, crescendo tanto nas matas ciliares como nos capões e capoeiras, na maioria das vezes sob a forma de arvoretas de tronco fino, pouco ramificado, com a folhagem brilhante e quando jovem levemente avermelhada. Além da Serra do Cipó, esta espécie ocorre também noutros locais da Cadeia do Espinhaço, como em Diamantina (MG) e na Serra do Sincorá (BA). Nesta última área, S. amara habita não só as matas ciliares mas também as extensas matas pluvio-nebulares que existem entre Mucugê, Andaraí e Lençóis, e ainda locais mais úmidos no meio do campo rupestre, sendo que neste último caso assumem porte reduzido.

o período de floração de $S$. amara na Serra do Cipó abrange os meses de abril a junho, e os frutos formam-se a partir de maio até outubro. Porter (1973) menciona, para as populações do Panamá, períodos fenológicos semelhantes, mas Aublet (1775) e Engler (1874) citam como meses férteis novembro e dezembro. Com base em todo o material estudado desta espécie proveniente de pontos diversos de toda sua área de distribuição, pode-se afirmar que globalmente ela pode florir de abril a dezembro; no entanto, parece haver pelo menos duas áreas geográficas com períodos de floração diferentes: espécimes com flores de abril a junho e frutos de maio a agosto só foram coletados, no Brasil, em Minas Gerais, enquanto nos estados do Norte e Nordeste, no istrito Federal e Mato Grosso, a espécie tem floração de agosto a dezembro. Assim, parece haver um isolamento entre as populações de $S$. amara de Minas Gerais e as da Bahia, por exemplo, e talvez as mesmas já constituam "raças geográficas"distintas, embora morfologicamente indistinguíveis.

$\mathrm{Nas}$ populações de $S$. amara das serras da Cadeia do Espinhaço, observa-se um evidente desvio na razão sexual, com um número bem maior de plantas estaminadas em relação às pistiladas, menos freqüentes, situação reportada como a mais comum para plantas dióicas tropicais por Bawa (1980) e Lloyd e Webb (1977), entre outros. As flores são perfumadas e aparecem em numerosas paniculas concentradas nas extremidades dos ramos, sendo a produção de flores por individuo sensivelmente maior nas plantas estaminadas. Os estiletes, inicialmente unidos, caem provavelmente lo:após a fecundação, e os carpelos começam a separar-se com a mat. 
ração, tornando-se em frutículos vináceos e sustentados pelo disco e pedicelo agora bem um pouco carnosos, $11-14)$.

espessados (Figuras

\section{Picramnia Sw.}

Arbustos a arvoretas. Folhas alternas, geralmente imparipinadas; foliolos alternos a opostos, pecillulados. Inflorescências alongadas, em racemos ou paniculas, geralmente terminais. Flores diclinas (em plantas dióicas), diminutas, 3-5-meras; sépalas persistentes no fruto; pétalas livres, imbricadas; estames 3-5, opostos às pétalas, reduzidos a estaminódios nas flores pistiladas; disco 3-5-1obado; gineceu 2-3(-4)-carpelar, sincárpico, rudimentar ou ausente nas flores estaminadas, 2-3(-4)-10cular; óvulos 2 por lóculo, subapicais, colaterais; estigmas $2-3(-4)$, divergentes, persistentes no fruto. Fruto bacáceo, 1-3-1ocular; sementes $1-2$ por lóculo.

\section{Chave para as espécies}

1. Sépalas e pétalas $3(-4)$; pétalas obovais emarginadas; folíolos glabros ou inferiormente com pêlos adpressos apenas nas nervuras e margem...................... glazioviana

1'. Sépalas e pétalas 5; pétalas lineares, agudas; folíolos densamente pilosos na face inferior............. 2. sellowii

1. Picramnia glazioviana Eng1. F1. Bras. 12(2): 242. 1874 .

Figs. 15-25

Nome vulgar: cafezinho-do-mato.

Arbustos a arvoretas $2,0-3,0 \mathrm{~m}$ alt., ramosos. Folha: imparipinadas, $15,0-32,0 \mathrm{~cm}$ compr., patentes; raque e pecíolo ad pressamente pilosos a glabros; folíolos 9-13(-14), alternos, ra ramente opostos, deflexos, distintamente articulados na base, os basais ovais e menores, os demais oblongo-elipticos a elípticos, 2,7-10,0 cm compr., 1,5-4,5 cm larg., cartáceos, ápice longamente acuminado, acúmen obtuso, margem revoluta, base assimétrica, gla-

Figs. 1-14 - Simarouba amara Aub1. 1 - Ramo com inflorescência estaminada, 2 Trecho de inflorescência pistilada, 3-Flor estaminada, 4 - A mesma em corte longitudinal, 5-6 - Estames, vistas lateral e dorsal, 7 - Flor pistilada, 8 A mesma, removida uma pétala, 9-10 - Estaminódios, vistas ventral e lateral, 11 - Gineceu e ginóforo em corte longitudinal, com estaminódios, 12 - Fruto com 4 carpídios, 13-14 - Carpídios, cortes longitudinal e transversal.

Figs. 1-14 - Simarouba amara Aubl. 1 - Staminate flowering shoot, 2 - A por tion from pistillate inflorescence, 3 - Staminate flower, 4 - Longitudin.. section of staminate flower, 5-6 - Stamens, lateral and dorsal views, 7 - Pis.. tillate flower, 8 - Pistillate flower without one petal, 9-10 - Staminodes, ventral and lateral view, 11 - Gynoecium and gynophore, longitudinal section, with staminodes, 12 - Fruit with 4 fruitlets, 13-14 - Fruitlets, longitudinal and transversal sections. 
Flora da Serra do Cipó: Simaroubaceae




bros ou inferiormente com pêlos adpressos nas nervuras e margem; nervuras pouco evidentes na face adaxial, salientes na abaxial. Paniculas terminais, laxamente multi-ramificadas, as staminadas $18,0-28,0 \mathrm{~cm}$ compr., as pistiladas 16,0-26,0 cm compr., delicadas e pendentes, eixo vináceo com indumento adpresso amarelado. F1ores 3(-4)-meras, vináceas, densamente agrupadas em glomérulos nos últimos ramos da panícula, 2,0-4,0 mm compr.; pedicelo e sépalas pilosos; sépalas ovais, obtusas; pétalas meméanáceas, oboval-espatuladas, emarginadas. Flores estaminadas: estames 3, inseridos entre os lobos do disco; pistilódio cilíndrico, piloso, reduzido. Flores pistiladas: estaminódios 3, obovados; disco 3-1obado; ovário $3(-4)$-carpelar, globoso, $3(-4)-1$ obado, pubérulo, $3(-4)-10 c u-$ lar; estigmas $3(-4)$, alongados, recurvados no ápice.

Material examinado: Santana do Riacho, Serra do Cipó, Rodovia Belo Horizonte - Conceição do Mato Dentro: km 127, Córrego Três Pontinhas, CFSC 7545, col. J.R. Pirani et al., 6.X.1981, f1.(SP, SPF); id., CFSC 7679, Col. J.R. Pirani \& I. Cordeiro, 3.XI.1981, f1. (SP, SPF).

Espécie com distribuição restrita à porção oriental do Sudeste brasileiro e sul da Bahia. O ponto mais ao centro do país em que já foi encontrada é a Serra do Cipó, onde tem reduzida expressão na flora, ocorrendo apenas no interior das matas ciliares, com pequeno número de individuos. Nesse local, a floração se dá entre outubro e novembro, mas na área global da espécie pode estender-se até janeiro e fevereiro.

2. Picramnia sellowii Planch. Lond. Jour. Bot. 5: 578. 1846.

Figs. 26-28

Arvoretas a árvores $3,0-4,0 \mathrm{~m}$ alt., copadas. Folhas imparipinadas, $10,0-25,0 \mathrm{~cm}$ compr.; raque e pecíolo densamente fulvo-tomentosos, às vezes o indumento com côr mais escura, acastanhada; folíolos 11-15, alternos, raramente subopostos, distintamente articulados na base, os basais oval-arredondados e meno-

Figs. 15-28 - Picramnia. 15-25 - P. glazioviana Engl. 15 - Ramo com inflorescência pistilada, 16 - Trecho de inflorescência estaminada em botão, 17 - Flor estaminada na antese, 18 - A mesma, removida uma sépala, 19 - Vista frontal de uma flor estaminada, foram removidas as metades terminais de dois estames, 20 - Flor pistilada, 21 - A mesma, removida uma pétala, 22 - Pétala da flor pistilada, 23 - Estaminódio, 24 - Flor pistilada em corte longitudinal, 25 - Ovário em corte transversal. 26-28 - P. sellowii Planch. 26 - Flor estaminada, 27 - Fruto, 28 - Fruto em corte longitudinal.

Figs. 15-28 - Picramnia. 15-25 - P. glazioviana Engl. 15 - Pistillate flowering shoot, 16 - A portion of staminate inflorescence, 17 - Staminate flower at anthesis, 18 - Staminate flower without one sepal, 19 - Staminate flower, frontal view, 20 - Pistillate flower, 21 - Pistillate flower without one petal, 22 - Petal from pistillate flower, 23 - Staminode, 24 - Pistillate flower, longitudinal section, 25 - Transversal section of ovary. 26-28 - P. sellowii Planch. 26 - Staminate flower, 27 - Fruit, 28 - Longitudinal section of fruit. 


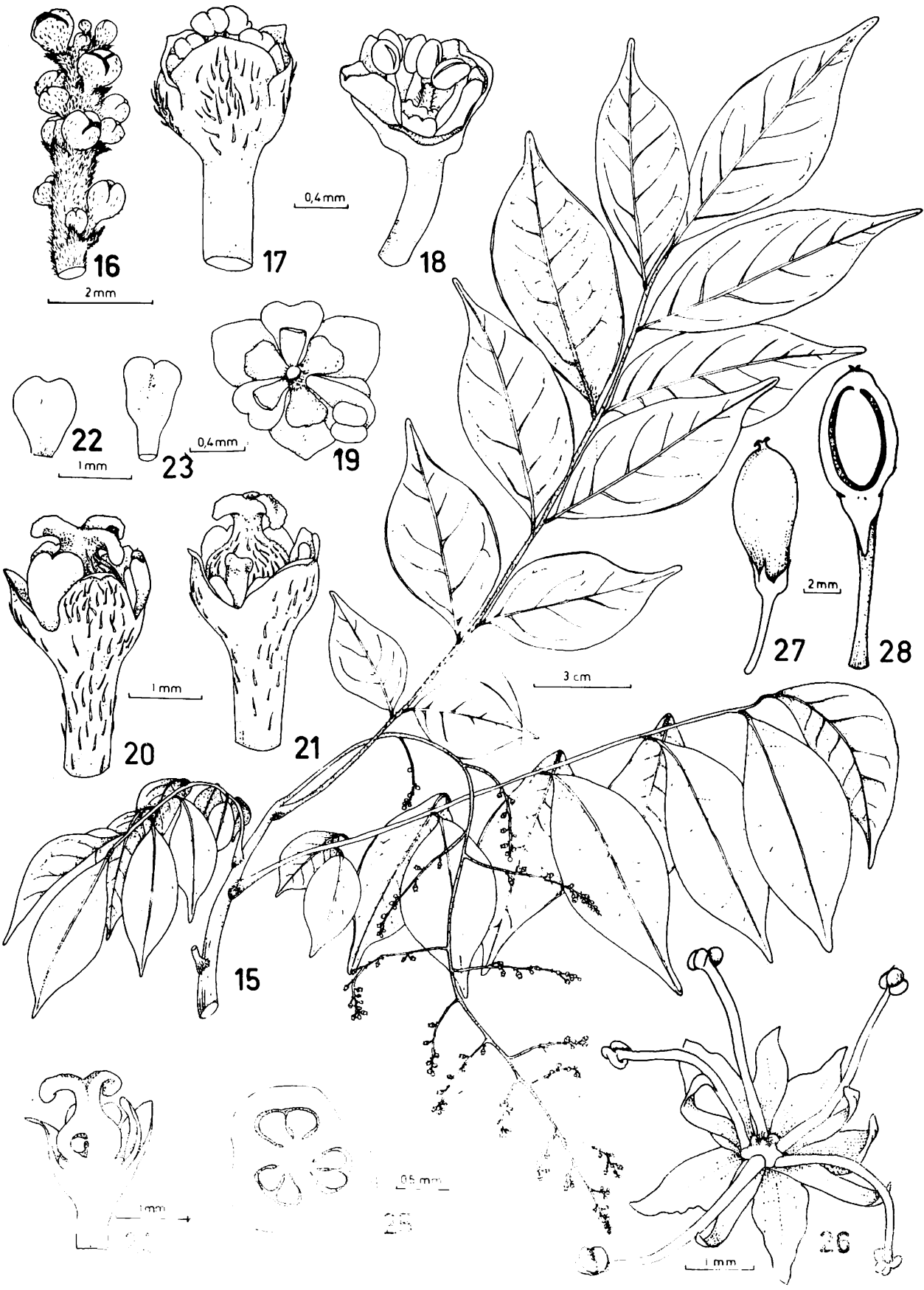


res, os demais oblongo-elipticos a elípticos, 2,0-7,5 cm compr., 1,0-3,0 cm larg., cartáceos, ápice atenuado a curtamente acuminado, acúmen obtuso, margem revoluta, base assimétrica, iace adaxial com pêlos apenas na nervura média a glabrescente, face abaxial densamente fulvo-tomentosa nas nervuras e margem; nervuras pouco evidentes na face adaxial, salientes na abaxial. Panículas estaminadas terminais, multi-ramificadas, 6,0-15,0 cm compr., pendentes, eixo densamente fulvo-tomentoso. Tlores estaminadas 5-meras, subsésseis, densamente agrupadas em glomérulos que se adensam para o ápice, ca. $3,0 \mathrm{~mm}$ compr.; pedicelo e sépalas pilosos; sépalas oval-lanceoladas, agudas; pétalas membranáceas, lineares, agudas; estames 5, inseridos entre os lobos do disco; pistilódio cilíndrico reduzido, no centro do disco. Frutos estreitamente obovóides, ca. 1,2 cm compr., 5,0 mm larg., glabros, com 2 estigmas no ápice, pedicelo $1,0-1,5 \mathrm{~cm}$ compr.

Material examinado: Jaboticatubas, margens do Rio Cipó, Mello Barreto 8684,19 . IV.1939, fr. (R); Santa Luzia, Fazenda do Cipó, Mello Baretto 9207, 20.IX.1937, f1.fr. (F, R, BнMH).

Esta é a espécie de Picramia mais amplamente distribuída pelo leste e centro-sul da América do Sul. Segundo Sleumer (1953), é espécie muito distribuída pelo Brasil, ocorrendo também no Paraguai e norte da Argentina. Nó Brasil, ocorre no Sul, Sudeste, Goiás, Mato Grosso e alguns estados do Nordeste. E facilmente identificável sobretudo pelo indumento denso e geralmente amarelado das folhas e inflorescências, pelos longos pedicelos das flores pistiladas fecundadas, e pelas 5 sépalas bem agudas.

A espécie exibe certo polimorfismo, e assim como varia a densidade e cor do indumento, também varia o tamanho das folhas, e portanto a distinção de uma variedade com folhas maiores ( $P$. sellowii var. latifolia Engl.) parece carecer de importância.

Como $P$. glazioviana, $P$. sellowii tem reduzida expressão na flora da Serra do Cipó; os materiais estudados são provenientes de áreas adjacentes e não das áreas mais elevadas da serra propriamente dita.

\section{REFERÊNCIAS}

AUBLET, F. 1775. Historie des plantes de la Guiane Française. vol. 2. Librairie de la Faculté de Médecine. Paris.

BAWA, K.S. 1980. Evolution of dioecy in flowering plants. Ann. Rev. Ecol. Syst. 11: 15-39.

CAVAlCANTE, P. 1983. Revisão taxonômica do gênero Simaba Aub1. (Simaroubaceae) na América do Sul. Publções avuls. Mus. Goeldi 37: 1-85.

CRONQUIST, A. 1944. Studies in the Simaroubaceae II. The genus Simarouba. Bu11. Torrey bot. Club. 71: 226-234.

ENGLER, A. 1874. Simaroubaceae. In C.F.P. Martius (ed.) Flora Brasiliensis 12 (2): $197-248$.

ENGLER, A. 1931. Simaroubaceae. In A. Engler \& K. Prantl (eds.) Die natürlichen Pflanzenfamilien ed. 2 19a: 359-405.

GIULIETTI, A.M., MENEZES, N.L., PIRANI, J.R., MEGURO, M. \& WANDERLEY, M.G.L. 1987. Flora da Serra do Cipó, Minas Gerais: Caracterização e lista das espécies. Bolm Botânica, Univ. S. Paulo 9: 1-151.

LLOYD, D.G. \& WEBB, C.J. 1977. Secondary sex characters in plants. Bot. Rev. 43: $177-216$.

NOOTEBOON, H.P. 1962. Generic delimitation in Simaroubaceae tribus Simaroubeae and a conspectus of the genus Quassia L. Blumea 11: 509-528.

PORTER, D.M. 1973. Flora of Panama. Simaroubaceae. Ann. Mo. hot. Gdn. 60:23-39. SLEUMER, H. 1953. Notas sobre la flora argentina II. Líl1oa 26: 161-175. 